\title{
Perceived Stigma in Remitted Psychiatric Patients and their Caregivers and its Association with Self-Esteem, Quality of Life, and Caregiver Depression
}

\author{
R Bipeta, SSRR Yerramilli, SV Pillutla
}

\begin{abstract}
Objectives: To examine perceived stigma and its correlates in remitted patients with mental illnesses and their caregivers.

Methods: In patients with mental illnesses, their perceived stigma (Perceived Devaluation Discrimination Scale), endorsed secrecy (Secrecy scale), self-esteem (Rosenberg Self-Esteem Scale), functioning (Work Social Adjustment Scale), and emotional wellbeing (Well Being Index) were assessed. In caregivers, their perceived stigma towards patients (Devaluation of Consumer Scale) and families (Devaluation of Consumer Families Scale), emotional wellbeing (Well Being Index), and depressive symptoms (Centre for Epidemiological Studies-Depression scale) were assessed. Differences between diagnoses were examined using ANOVA. Correlation between perceived stigma among patients and caregivers was studied.

Results: Of 152 patients with mental illnesses, $76.3 \%$ and $85.53 \%$ reported moderate-to-high levels of perceived stigma and endorsed secrecy, respectively. Of 152 caregivers, $40.13 \%$ and $25.65 \%$ reported moderate-to-high levels of perceived stigma towards patients and families, respectively. Overall, patients had high levels of perceived stigma and endorsed secrecy, low self-esteem, moderate functional impairment, and extremely poor emotional wellbeing. There were significant differences across different diagnostic categories with respect to self-esteem, functioning, perceived stigma, secrecy, and emotional wellbeing. Patients with substance use disorders reported highest perceived stigma, lowest self-esteem, and most severe functional impairment, and their caregivers reported highest perceived stigma towards patients and families, most-reduced emotional wellbeing, and highest rates of depressive symptoms. Patients' perceived stigma was not associated with caregivers' perceived stigma.

Conclusion: Perceived stigma is prevalent among patients and caregivers and affects their quality of life. The stigma associated with substance use disorder merits special attention.
\end{abstract}

Key words: Caregivers; Mental disorders; Patients; Self concept; Social stigma

Rajshekhar Bipeta, Rajasri Clinic, Hyderabad, Telangana, India Srinivasa SRR Yerramilli, Sri Venkateswara Nursing Home, Hyderabad, Telangana, India

Sri Vidya Pillutla, Hyderabad, Telangana, India

Address for correspondence: Dr Rajshekhar Bipeta, Rajasri Clinic, RTC Cross Roads, Chikkadpalli, Hyderabad-500020. Telangana, India.

Email:braj111@yahoo.co.in

\section{Introduction}

Patients with mental illnesses experience prejudice and discrimination by the general population. Public stigma towards patients with mental illnesses is based on negative stereotypes: notions that these people are dangerous, weak, or incompetent. The negative stereotypes evolve from and are defined by society. Members of the public may or may not agree with these negative stereotypes. Those who endorse these negative stereotypes develop adverse emotional reactions (prejudice) and negative behavioural responses (discrimination) towards such patients. ${ }^{1}$

Patients with mental illnesses may recognise that the public holds prejudice and discrimination against them. This is known as perceived stigma. ${ }^{2}$ Perceived stigma leads to internalised or self-stigma when patients with mental illnesses accept the public stigma, incorporate it into their self-concept, and apply it to themselves. ${ }^{3}$

Self-stigma includes an endorsement of the negative stereotypes ("I am weak"), self-prejudice ("I am incompetent because I am weak"), and consequently, selfdiscrimination (eg, "I cannot handle a job"). On internalising the negative stereotypes, these patients may have adverse emotional reactions, diminished self-esteem, ${ }^{4}$ and reduced self-efficacy. ${ }^{5}$ Patients with self-stigma may not be able to avail employment and independent-living opportunities, ${ }^{4,6}$ and have feelings of reduced self-worth. Furthermore, perceived and self-stigma may result in avoidance and self-isolation. ${ }^{7}$ Patients may adopt secrecy as an adaptive response in anticipation of private or public shame. They may not disclose their problems even to their close relatives, 
creating barriers to treatment. Thus, perceived and selfstigma have many harmful effects such as reduced helpseeking and treatment adherence, poor health outcomes, and poor quality of life. ${ }^{6,8}$ Self-stigmatising patients worsen the course of their mental illness owing to the additional adverse effects of the perceived and internalised stigma.

Patients with mental illnesses and their caregivers bear the burden of stigma, in addition to the economic and material burden in caring for the patients. ${ }^{9,10} 43 \%$ of the caregivers reported feeling stigmatised. ${ }^{11}$ Half of the 156 family members of patients with mental illnesses have made efforts to conceal the patient's illness. ${ }^{12}$ The effect of caregiver stigma is greater in resource-poor countries such as India where the burden of mental illness is very high and families are the primary caregivers. Despite recommendations to consider caregivers as part of the healthcare system, ${ }^{13}$ few studies on stigma have involved caregivers.

The effect of cultural variables on the stigmatisation of patients and caregivers is not well studied..$^{14}$ This may have public health significance, as stigma is culturally determined, and extrapolation from non-local studies may not be applicable. There are few studies on perceived stigma in patients and caregivers in India. Thus, the present study aimed to examine the level of perceived stigma and its associations with self-esteem, functioning, and emotional wellbeing in patients with mental illnesses, its association with emotional wellbeing and depression in their caregivers, and its association between patients and caregivers.

\section{Methods}

This cross-sectional study was approved by the MAARG Independent Ethics Committee, Secunderabad, India (AR/3005) and was conducted in accordance with the principles of the Declaration of Helsinki. Written informed consent was obtained from each participant. We purposively sampled outpatients of two private psychiatric clinics in India between 2016 and 2018 who were aged $\geq 18$ years and had shown remission. Patients were considered to be in remission if they were on regular treatment, clinically stable, and scored $\leq 2$ in the Clinical Global Impressions Scale-severity. ${ }^{15,16}$ Patients with substance use disorders (SUD) were considered to be in remission if they did not meet the syndromal criteria for substance-harmful use or dependence for a minimum of 6 months, ${ }^{17}$ based on the clinician's judgement. Those with comorbid Axis-I disorder, dual diagnosis, personality disorders, learning disabilities, mental retardation, dementia, or major uncontrolled medical illnesses/surgeries (within a year) were excluded.

Caregivers were defined as "a friend or family member most involved in care of the patient, that is the person who responds in an emergency, attends appointments, provides financial assistance, or interacts on a daily basis". ${ }^{18}$ Caregivers who had diagnosable psychiatric illnesses (except for psychosocial issues, adjustment problems or depressive symptoms directly attributable to patients' illnesses), SUDs, or a major uncontrolled medical illness or surgery (within a year) were excluded.

The diagnosis of psychiatric disorders was made according to the ICD- $10^{19}$ by psychiatrists with extensive experience. The word 'stigma' was avoided so as not to lead patient perception. Severity of illness was assessed using the Clinical Global Impressions Scale-severity. ${ }^{15}$ Global self-esteem was measured using the Rosenberg SelfEsteem Scale (RSES).$^{20}$ Scores range from 0 to 30; scores of $<15$ indicate low self-esteem. Adaptive work and social functioning were evaluated using the Work and Social Adjustment Scale (WSAS). ${ }^{21}$ Scores range from 0 to 40; higher scores indicate more inadequate adjustment. Patients' perceived stigma was measured using the 12 -item Perceived Devaluation and Discrimination Scale (PDDS) ${ }^{2,22,23}$ Each item was rated on a 4-point Likert scale from 1 (strongly agree) to 4 (strongly disagree). The scale is balanced such that a high level of perceived stigma is indicated by agreement with six of the items and by disagreement with six others. Items are appropriately recoded so that higher scores indicate greater perceived stigma. Scores range from 12 to 48; higher scores indicate higher perceived stigma. According to the GAMIAN-Europe study, the total score is divided by 12 and scores of $\geq 2.5$ were taken as moderate stigma and $>3$ as high stigma. ${ }^{24}$ The prevalence of moderateto-high perceived stigma was then estimated. The degree a person endorsed secrecy as a means of avoiding rejection was assessed using the 9-item Secrecy scale (SS), ${ }^{22,23}$ which is a subscale of the Link stigma scale. Scores range from 9 to 36; higher scores indicate higher endorsed secrecy.

Caregivers' perceived stigma was assessed using two measures. The 8-item Devaluation of Consumer Scale $(D C S)^{11}$ provides the basis for operationally defining the devaluation of consumers who have serious mental illness from the caregivers' perspective. Higher scores indicate greater perceived stigma. The 7-item Devaluation of Consumer Families Scale (DCFS) ${ }^{11}$ estimates the extent to which caregivers believe that most people devalue families that include one or more persons who have serious mental illness. Higher scores indicate more severe stigma. The 20-item Centre for Epidemiological Studies-Depression (CES-D) scale $^{25}$ was used to measure the presence of depressive symptoms. Scores range from 0 to 60 ; higher scores indicate more severe depressive symptoms.

Most of the scales (RSES, ${ }^{26}$ WSAS,${ }^{27}$ PDDS,${ }^{28}$ DCS and DCFS, ${ }^{29}$ and CES-D ${ }^{30}$ ) have been used in the Indian population. RSES is a psychometrically sound measure for self-esteem $(\alpha=0.81) .{ }^{31}$ The CES-D has fare reliability and robust convergent validity (Cronbach's alpha $=0.70$ ) in terms of conceptually related measures. ${ }^{32}$

Emotional wellbeing of patients and caregivers was assessed using the 5-item World Health Organization Well Being Index (WHO-5). ${ }^{33}$ Scores range from 0 to 25; scores $<13$ indicate poor emotional wellbeing.

As there was no prior study measuring perceived stigma to guide our calculation of effect size, and perceived stigma varies across different psychiatric diagnoses, a 
conservative approach and a small effect size were used. There were five dependent variables and four groups. Using G-POWER, ${ }^{34} 38$ patients were required for each group to achieve a low effect size of $0.25, \alpha$ (type I error) of 0.05 , and power of $80 \%$.

Statistical analyses were performed using SPSS (Windows version 23; IBM Corp, Armonk [NY], US). Multivariate analysis of variance (ANOVA) was used to examine between-diagnosis differences. The associations between patients' perceived stigma (PDDS) and their self-esteem, functioning, and emotional wellbeing were determined using correlational analysis, as were associations between caregivers' perceived stigma towards patients (DCS) and families (DCFS) and their emotional wellbeing and depression, and associations between patients' and caregivers' perceived stigma.

\section{Results}

A total of 83 female and 69 male patients (mean age, $31.2 \pm$ 9.0 years) were included. Their diagnoses were evenly distributed to four groups: SUDs (harmful use, dependence), psychotic disorders (schizophrenia, delusional disorder), affective disorders (bipolar disorder, mania, bipolar depression, and depressive disorders), and neurotic and related disorders (anxiety disorders, obsessive-compulsive disorder), with 38 (25\%) patients in each group. 48 (31.6\%) patients completed higher secondary education, and the remaining $104(68.4 \%)$ completed graduate education or above. $66(43.4 \%)$ patients were single (never married, separated, divorced), and the remaining $86(56.6 \%)$ were married.

A total of 80 female and 72 male caregivers (mean age, $37.9 \pm 14.1$ years) were included. Most were spouses of the patients $(n=57,37.5 \%)$, followed by parents $(n=52,34.2 \%)$, children $(\mathrm{n}=19,12.5 \%)$, and siblings, friends or in-laws $(n=24,15.8 \%) .97$ (63.8\%) completed graduate education or above, and the remaining 55 (36.2\%) completed higher secondary education.
Of the 152 patients, $76.3 \%$ and $85.53 \%$ reported moderate-to-high levels of perceived stigma (PDDS) and endorsed secrecy (SS), respectively. Among the caregivers, $40.13 \%$ and $25.65 \%$ reported moderate-to-high levels of perceived stigma towards patients (DCS) and families (DCFS), respectively (Table 1). Overall, patients had high levels of perceived stigma and endorsed secrecy, low selfesteem (mean RSES score, 13.8), moderate functional impairment (mean WSAS score, 24.7), and extremely poor emotional wellbeing (mean WHO-5 score, 7.4) [Table 2].

The Box's M test for equality of covariance matrices was significant $(\mathrm{p}<0.001)$. Therefore, the Pillai trace test $^{35}$ was used (Pillai trace $=0.79$, F $(15,438)=10.50$, $\mathrm{p}<0.001$, eta squared $=0.27$ ). There were significant differences across different diagnostic categories with respect to self-esteem, functioning, perceived stigma, secrecy, and emotional wellbeing. Approximately $27 \%$ of the multivariate variance of these factors was associated with the diagnostic categories. Thus, univariate ANOVAs were performed. To control for type I error, Bonferroni correction was used, and each ANOVA was tested at the 0.01 level. All five univariate ANOVAs were significant: RSES $(\mathrm{F}(3,148)=7.92, \mathrm{p}<0.001$, eta squared $=0.14)$, WSAS $(\mathrm{F}(3,148)=12.60, \mathrm{p}<0.001$, eta squared $=0.20)$, WHO-5 $(\mathrm{F}(3,148)=11.97, \mathrm{p}<0.001$, eta squared $=0.20)$, and PDDS $(\mathrm{F}(3,148)=11.30, \mathrm{p}<0.001$, eta squared $=0.29)$, and $\operatorname{SS}(\mathrm{F}(3,148)=20.48, \mathrm{p}<0.001$, eta squared $=0.19)$.

The Tukey post hoc test was used. To control for type I error across multiple pairwise comparisons for dependent variables at the 0.01 alpha level, each comparison was tested at the alpha level for the ANOVA divided by the number of comparisons $(0.01 / 3=0.0033$ for our sample). Self-esteem was significantly lower in those with SUDs than psychotic disorders or affective disorders (mean RSES score, 10.6 vs 16.0 vs 15.6). Functional impairment was significantly higher in those with SUDs than affective disorders or neurotic disorders (mean WSAS score, 29.9 vs 20.3 vs 21.6) and in those with psychotic disorders than affective disorders (mean WSAS score, 27.2 vs 20.3). Emotional

Table 1. Distribution of patients and caregivers in terms of various scales for perceived stigma ( $n=152)$

\begin{tabular}{|lccccc|}
\hline & Mean \pm SD & \multicolumn{3}{c|}{ Patients' perceived stigma (Perceived Devaluation and } \\
Discrimination Scale)
\end{tabular}

Data are presented as no. (\%) of patients / caregivers 
wellbeing was better in those with affective disorders than SUDs or neurotic disorders (mean WHO-5 score, 11.9 vs 4.9 vs 4.6). Perceived stigma was higher in those with SUDs than neurotic disorders, affective disorders or psychotic disorders (mean PDDS score, 40.1 vs 35.5 vs 31.5 vs 33.5). Endorsed secrecy was lower in those with neurotic disorders than psychotic disorders or SUDs (23.4 vs 28.4 vs 27.0).
Patients' perceived stigma was significantly associated with self-esteem, functioning, and emotional wellbeing ( $\mathrm{p}<0.001$ for all, Table 3 ).

Caregivers' perceived stigma towards patients (DCS) and families (DCFS) was highest in caregivers of patients with SUDs, followed by psychotic disorders, affective disorders, and neurotic disorders (Table 4). Emotional

Table 2. Differences in patients' self-esteem, functioning, emotional wellbeing, perceived stigma, and endorsed secrecy across different diagnostic categories

\begin{tabular}{|lccccc|}
\hline Diagnostic category & $\begin{array}{c}\text { Rosenberg } \\
\text { Self-Esteem } \\
\text { Scale }\end{array}$ & $\begin{array}{c}\text { Work and } \\
\text { Social } \\
\text { Adjustment } \\
\text { Scale }\end{array}$ & $\begin{array}{c}\text { WHO-5 } \\
\text { Item Well } \\
\text { Being Index }\end{array}$ & $\begin{array}{c}\text { Perceived } \\
\text { Devaluation } \\
\text { and } \\
\text { Discrimination } \\
\text { Scale }\end{array}$ & $\begin{array}{c}\text { Secrecy } \\
\text { Scale }\end{array}$ \\
Substance use disorders $(\mathrm{n}=38)$ & $10.6 \pm 3.6$ & $29.9 \pm 5.0$ & $4.9 \pm 4.8$ & $40.1 \pm 2.8$ & $27.0 \pm 2.1$ \\
\hline Psychotic disorders $(\mathrm{n}=38)$ & $16.0 \pm 5.8$ & $27.2 \pm 6.0$ & $8.2 \pm 6.0$ & $33.5 \pm 6.1$ & $28.4 \pm 3.1$ \\
\hline Affective disorders $(\mathrm{n}=38)$ & $15.6 \pm 6.8$ & $20.3 \pm 11.2$ & $11.9 \pm 8.9$ & $31.5 \pm 6.2$ & $26.0 \pm 3.1$ \\
\hline Neurotic and related disorders $(\mathrm{n}=38)$ & $13.0 \pm 5.4$ & $21.6 \pm 8.0$ & $4.6 \pm 3.2$ & $35.5 \pm 4.0$ & $23.4 \pm 6.1$ \\
\hline Overall & $\mathbf{1 3 . 8} \pm \mathbf{5 . 9}$ & $\mathbf{2 4 . 7} \pm \mathbf{8 . 8}$ & $\mathbf{7 . 4} \pm \mathbf{6 . 7}$ & $\mathbf{3 5 . 2} \pm \mathbf{5 . 9}$ & $\mathbf{2 6 . 2} \pm \mathbf{4 . 3}$ \\
\hline
\end{tabular}

* Significant pairwise comparisons on the Tukey post-hoc test at an $\alpha$-level of 0.0033

Table 3. Correlations of patients' perceived stigma and self-esteem, functioning, and emotional wellbeing

\begin{tabular}{|lcccc|}
\hline Diagnostic category & $\begin{array}{c}\text { Rosenberg } \\
\text { Self-Esteem } \\
\text { Scale }\end{array}$ & $\begin{array}{c}\text { Work and Social } \\
\text { Adjustment Scale }\end{array}$ & $\begin{array}{c}\text { Perceived } \\
\text { Devaluation and } \\
\text { Discrimination } \\
\text { Scale }\end{array}$ & Secrecy Scale \\
Rosenberg Self-Esteem Scale & 1 & $-0.26(\mathrm{p}=0.001)$ & $0.162(\mathrm{p}=0.046)$ & $-0.32(\mathrm{p}<0.001)$ \\
\hline Work and Social Adjustment Scale & -0.26 & 1 & $-0.28(\mathrm{p}<0.001)$ & $-0.36(\mathrm{p}<0.001)$ \\
\hline WHO-5 Item Well Being Index & & & 1 & $-0.36(\mathrm{p}<0.001)$ \\
\hline $\begin{array}{l}\text { Perceived Devaluation and } \\
\text { Discrimination Scale }\end{array}$ & & & & 1 \\
\hline
\end{tabular}

Table 4. Differences in caregivers' perceived stigma, emotional wellbeing, and depressive symptoms across different diagnostic categories

\begin{tabular}{|lcccc|}
\hline Diagnostic category & $\begin{array}{c}\text { Devaluation of } \\
\text { Consumer Scale }\end{array}$ & $\begin{array}{c}\text { Devaluation } \\
\text { of Consumer } \\
\text { Families Scale }\end{array}$ & $\begin{array}{c}\text { WHO-5 Item Well } \\
\text { Being Index }\end{array}$ & $\begin{array}{c}\text { Centre for } \\
\text { Epidemiological } \\
\text { Studies- } \\
\text { Depression scale }\end{array}$ \\
\hline Substance use disorders & $19.7 \pm 7.3$ & $17.2 \pm 6.3^{*}$ & $11.0 \pm 4.0$ & $34.4 \pm 12.8^{*}$ \\
\hline Psychotic disorder & $17.0 \pm 8.4$ & $14.3 \pm 6.7$ & $13.1 \pm 6.3$ & $26.2 \pm 16.5$ \\
\hline Affective disorder & $15.2 \pm 7.2$ & $12.7 \pm 5.0$ & $14.7 \pm 5.9$ & $22.6 \pm 13.1^{*}$ \\
\hline Neurotic and related disorders & $14.8 \pm 6.9$ & $12.2 \pm 5.6^{*}$ & $12.4 \pm 4.6$ & $23.7 \pm 13.8$ \\
\hline Overall & $\mathbf{1 6 . 7} \pm \mathbf{7 . 6}$ & $\mathbf{1 4 . 1} \pm \mathbf{6 . 2}$ & $\mathbf{1 2 . 8} \pm \mathbf{5 . 4}$ & $\mathbf{2 6 . 7} \pm \mathbf{1 4 . 7}$ \\
\hline
\end{tabular}

Significant pairwise comparisons in the Tukey post hoc test at an $\alpha$-level of 0.0042 
wellbeing was poorest in caregivers of patients with SUDs, followed by neurotic disorders, psychotic disorders, and affective disorders. Depressive symptoms were most severe in caregivers of patients with SUDs, followed by psychotic disorders, neurotic disorders, and affective disorders. There were significant differences between diagnostic categories and assessment scores $(\mathrm{F}(12,384)=2.604, \mathrm{p}=0.002$, Wilk's lambda $=0.813$, partial eta squared $=0.067$ ). After Bonferroni correction, two of the four univariate ANOVAs were significant at the 0.0125 adjusted alpha level: DCFS $(\mathrm{F}(3,148)=5.46, \mathrm{p}=0.001$, partial eta squared $=0.1)$ and CES-D $(\mathrm{F}(3,148)=5.38, \mathrm{p}=0.002$, partial eta squared $=$ $0.098)$. The Tukey post hoc test showed significant pairwise differences in DCFS scores between caregivers of patients with SUDs versus neurotic disorder (17.2 vs 12.2) and in CES-D scores between caregivers of patients with SUDs versus affective disorders (34.4 vs 22.6).

Patients' perceived stigma (PDDS and SS) was not associated with caregivers' perceived stigma towards patients and families (DCS and DCFS) [Spearman's rho correlation coefficient $=0.076, \mathrm{p}=0.352,2$-tailed] .

\section{Discussion}

In the present study, $76.32 \%$ and $85.53 \%$ of patients with mental illnesses reported moderate-to-high levels of perceived stigma and endorsed secrecy, respectively; the percentages are lower than the $93 \%$ but higher than the $51.5 \%{ }^{37}$ reported elsewhere.

Stigma has harmful effects on patients with mental illnesses. ${ }^{4,6,37,38}$ The present study reported low self-esteem, poor emotional wellbeing, and maladjusted work and functioning in patients with mental illnesses. Stigma implies fear of branding, discrimination, social isolation, criticism by others, lower status in the society. Stigma affects patients and their families. Caregivers with higher perceived stigma experience more emotional distress. ${ }^{14}$ Taking care of patients with mental illnesses is stressful and affects the health and wellbeing of caregivers in the longer run.

Patients with SUDs had the highest perceived stigma and endorsed secrecy and most impaired functioning, selfesteem, and emotional wellbeing. This is in keeping with other studies reporting higher perceived stigma in patients with SUDs than other mental illnesses..$^{39-41}$ Negative social attitudes may partly explain the high perceived stigma towards patients with SUDs. In addition, caregivers' perceived stigma towards patients and families was also highest in caregivers of patients with SUDs who also had the most impaired emotional wellbeing and most severe depressive symptoms. Society views SUD as an evil or defect of character rather than a medical disorder.

Patients with psychotic disorders reported the highest endorsed secrecy, with poor emotional wellbeing and high functional impairment. Correspondingly, their caregivers' perceived stigma towards patients and families, emotional wellbeing, and depressive symptoms were high, although of lower magnitude than that of caregivers of patients with SUDs. Suspiciousness and disorganised thinking are characteristic of psychotic disorders despite remission. However, a study reported no significant correlations between self-stigma and psychotic symptoms. ${ }^{14}$

Patients with affective disorders reported the lowest perceived stigma and highest levels of emotional wellbeing and functioning. They had better self-esteem than patients with SUDs or psychotic disorders. Caregivers of patients with affective disorders also had the highest emotional wellbeing and least depressive symptoms.

Patients with neurotic disorders reported high perceived stigma and low levels of emotional wellbeing and functioning. However, caregivers of patients with neurotic disorders reported the lowest perceived stigma towards patients and families and lower depressive symptom scores. The difference in perception between patients with neurotic disorders and their caregivers could be partly explained by the insight among patients with neurotic disorders who know that they have a mental illness and hence higher perceived stigma. Self-stigma is associated with insight and quality of life.$^{14}$ However, these factors may not have a negative effect on caregivers.

There was no significant correlation between the perceived stigma of the patients and caregivers, consistent with a study of patients with first-episode psychosis. ${ }^{14}$ The mechanism of development of stigma may differ between patients and caregivers. The determinants of perceived stigma and effects of different diagnoses on patients and caregivers may differ. Caregivers of patients with psychotic disorders or SUDs may be more likely to be affected by the bizarre behaviour of patients and result in higher perceived stigma and depressive symptoms, compared with caregivers of patients with neurotic conditions.

Despite increased awareness, perceived stigma remains high among patients and their families. Further research is warranted to determine the correlates of perceived and self-stigma in Indian patients with mental illnesses to formulate stigma-reduction programmes for this population.

The results should be interpreted in the context that the study was conducted in an urban setting, with a small sample, and may not be generalisable to the Indian population. The study used self-reported data from a crosssectional sample without controls. The study was unblinded, and instruments such as WSAS, PDDS, DCS, and DCFS are not standardised for the Indian population.

\section{Conclusion}

Perceived stigma is prevalent among patients and caregivers and affects their quality of life. Our findings may enable clinicians to empower patients and their caregivers to manage the stigma. The determinants of stigma differ between patients and their caregivers. Further studies are needed to determine the predicates and formulate measures to ameliorate this stigma. 


\section{Acknowledgements}

We thank Prof Majeed A Khan, consultant psychiatrist, Hyderabad, India, for his contribution to the conceptualisation of this study. He expired on 10 May 2015. We thank Ms Romana Zulfiqar, Romed Communications, New Delhi, India, for providing statistical assistance and helping in the preparation of this manuscript in the form of writing, copy-editing, and proof-reading.

\section{Funding/support}

This research received no specific grant from any funding agency in the public, commercial, or not-for-profit sectors.

\section{Declaration}

All authors have no conflict of interest to disclose.

\section{Author contributions}

Concept or design: RB

Acquisition of data: All authors

Analysis or interpretation of data: All authors

Drafting of the article: All authors

Critical revision for important intellectual content: All authors

All authors had full access to the data, contributed to the study, approved the final version for publication, and take responsibility for its accuracy and integrity.

\section{References}

1. Corrigan PW, Watson AC. Understanding the impact of stigma on people with mental illness. World Psychiatry 2002;1:16-20.

2. Link BG. Understanding labeling effects in the area of mental disorders: an assessment of the effects of expectations of rejection. Am Sociol Rev 1987;52:96-112. Crossref

3. Corrigan PW, Rao D. On the self-stigma of mental illness: stages, disclosure, and strategies for change. Can J Psychiatry 2012;57:4649. Crossref

4. Yanos PT, Roe D, Markus K, Lysaker PH. Pathways between internalised stigma and outcomes related to recovery in schizophrenia spectrum disorders. Psychiatr Serv 2008;59:1437-42. Crossref

5. Watson AC, Corrigan P, Larson JE, Sells M. Self-stigma in people with mental illness. Schizophr Bull 2007;33:1312-8. Crossref

6. Lysaker PH, Roe D, Yanos PT. Toward understanding the insight paradox: internalized stigma moderates the association between insight and social functioning, hope, and self-esteem among people with schizophrenia spectrum disorders. Schizophr Bull 2007;33:1929. Crossref

7. Link BG, Struening EL, Rahav M, Phelan JC, Nuttbrock L. On stigma and its consequences: evidence from a longitudinal study of men with dual diagnoses of mental illness and substance abuse. J Health Soc Behav 1997;38:177-90. Crossref

8. Vauth R, Kleim B, Wirtz M, Corrigan PW. Self-efficacy and empowerment as outcomes of self-stigmatizing and coping schizophrenia. Psychiatry Res 2007;150:71-80. Crossref

9. Larson JE, Corrigan P. The stigma of families with mental illness. Acad Psychiatry 2008;32:87-91. Crossref

10. Magliano L, Marasco C, Fiorillo A, Malangone C, Guarneri M, Maj M, et al. The impact of professional and social network support on the burden of families of patients with schizophrenia in Italy. Acta Psychiatr Scand 2002;106:291-8. Crossref

11. Struening EL, Perlick DA, Link BG, Hellman F, Herman D, Sirey JA. Stigma as a barrier to recovery: the extent to which caregivers believe most people devalue consumers and their families. Psychiatr Serv 2001;52:1633-8. Crossref

12. Phelan JC, Bromet EJ, Link BG. Psychiatric illness and family stigma. Schizophr Bull 1998;24:115-26. Crossref

13. Tessler R, Gamache G. Evaluating family experiences with severe mental illness. Cambridge, MA: Human Services Research Institute; 1993.

14. Chen ES, Chang WC, Hui CL, Chan SK, Lee EH, Chen EY. Selfstigma and affiliate stigma in first-episode psychosis patients and their caregivers. Soc Psychiatry Psychiatr Epidemiol 2016;51:122531. Crossref

15. Guy W. Clinical Global Impressions. ECDEU Assessment Manual for Psychopharmacology. U.S. Department of Health, Education, and Welfare; 1976. Crossref

16. Busner J, Targum SD. The clinical global impressions scale: applying a research tool in clinical practice. Psychiatry (Edgmont) 2007;4:28-37.

17. Fleury MJ, Djouini A, Huỳnh C, Tremblay J, Ferland F, Ménard JM, et al. Remission from substance use disorders: a systematic review and meta-analysis. Drug Alcohol Depend 2016;168:293-306. Crossref

18. Gonzalez JM, Perlick DA, Miklowitz DJ, Kaczynski R, Hernandez M, Rosenheck RA, et al. Factors associated with stigma among caregivers of patients with bipolar disorder in the STEP-BD study. Psychiatr Serv 2007;58:41-8. Crossref

19. World Health Organization. International Statistical Classification of Diseases and Related Health Problems, 10th Revision (ICD-10). Geneva: WHO; 1992.

20. Rosenberg M. Society and the Adolescent Self-Image. Princeton University Press; 1965 . Crossref

21. Mundt JC, Marks IM, Shear MK, Greist JH. The Work and Social Adjustment Scale: a simple measure of impairment in functioning. $\mathrm{Br}$ J Psychiatry 2002;180:461-4. Crossref

22. Link BG, Cullen FT, Struening EL, Shrout PE, Dohrenwend BP. A modified labeling theory approach to mental disorders: an empirical assessment. Am Sociol Rev 1989;54:400-23. Crossref

23. Link BG, Struening EL, Neese-Todd S, Asmussen S, Phelan JC. On describing and seeking to change the experience of stigma. Psychiatr Rehabil Skills 2002;6:201-31. Crossref

24. Brohan E, Elgie R, Sartorius N, Thornicroft G; GAMIAN-Europe Study Group. Self-stigma, empowerment and perceived discrimination among people with schizophrenia in 14 European countries: the GAMIAN-Europe study. Schizophr Res 2010;122:232-8. Crossref

25. Radloff LS. The CES-D Scale: a self-report depression scale for research in the general population. Appl Psychol Meas 1977;1:385-401. Crossref

26. Gandhi S, Pavalur R, Thanapal S, Parathasarathy NB, Desai G, Bhola $\mathrm{P}$, et al. Medication adherence, work performance and self-esteem among psychiatric patients attending psychosocial rehabilitation services at Bangalore, India. Indian J Psychol Med 2014;36:392-6. Crossref

27. Aggarwal A, Unni KES, Prasad S. A comparative study of stress, anxiety \& work impairment in parents of children with conduct disorder. J Indian Assoc Child Adolesc Ment Health 2018;14:15-37.

28. Boge K, Zieger A, Mungee A, Tandon A, Fuchs LM, Schomerus G, et al. Perceived stigmatisation and discrimination of people with mental illness: a survey-based study of the general population in five metropolitan cities in India. Indian J Psychiatry 2018;60:24-31. Crossref

29. Pawar AA, Peters A, Rathod J. Stigma of mental illness: a study in the Indian Armed Forces. Med J Armed Forces India 2014;70:3549. Crossref

30. Mathew AC, Benny E, Osborn JA, Rajasekaran SK, Prabu SR, Yunsheng M. Association between sleep duration and glycemic control among patients with type 2 diabetes mellitus in India. Indian Sleep Med 2014;9:22-8. Crossref

31. Schmitt DP, Allik J. Simultaneous administration of the Rosenberg Self-Esteem Scale in 53 nations: exploring the universal and culture- 
specific features of global self-esteem. J Pers Soc Psychol 2005;89:62342. Crossref

32. Chokkanathan S, Mohanty J. Factor structure of the CES-D scale among older adults in Chennai, India. Ageing Ment Health 2013;17: 517-25. Crossref

33. Development of the World Health Organization WHOQOL-BREF quality of life assessment. The WHOQOL Group. Psychol Med 1998;28:551-8. Crossref

34. Buchner A. G*Power: Statistical Power Analyses. https://www. psychologie.hhu.de/en/research-teams/cognitive-and-industrialpsychology/gpower.html. Accessed 7 July 2020.

35. Nimon KF. Statistical assumptions of substantive analyses across the general linear model: a mini-review. Front Psychol 2012;3:322. Crossref

36. Farrelly S, Clement S, Gabbidon J, Jeffery D, Dockery L, Lassman F, et al. Anticipated and experienced discrimination amongst people with schizophrenia, bipolar disorder and major depressive disorder: a crosssectional study. BMC Psychiatry 2014;14:157. Crossref

37. Oshodi YO, Abdulmalik J, Ola B, James BO, Bonetto C, Cristofalo D, et al. Pattern of experienced and anticipated discrimination among people with depression in Nigeria: a cross-sectional study. Soc Psychiatry Psychiatr Epidemiol 2014;49:259-66. Crossref

38. Perlick DA, Rosenheck RA, Clarkin JF, Sirey JA, Salahi J, Struening EL, et al. Stigma as a barrier to recovery: adverse effects of perceived stigma on social adaptation of persons diagnosed with bipolar affective disorder. Psychiatr Serv 2001;52:1627-32. Crossref

39. Corrigan PW, Kuwabara SA, O'Shaughnessy J. The public stigma of mental illness and drug addiction: findings from a stratified random sample. J Soc Work 2009;9:139-47. Crossref

40. Rasinski KA, Woll P, Cooke A. Stigma and Substance Use Disorders. In: Corrigan PW, editor. On the Stigma of Mental Illness: Practical Strategies for Research and Social Change. American Psychological Association; 2005: 219-36. Crossref

41. Schomerus G, Lucht M, Holzinger A, Matschinger H, Carta MG, Angermeyer MC. The stigma of alcohol dependence compared with other mental disorders: a review of population studies. Alcohol Alcohol 2011;46:105-12. Crossref 